\title{
Variables that Predict Serve Efficacy in Elite Men's Volleyball with Different Quality of Opposition Sets
}

\author{
by \\ Álvaro Valhondo ${ }^{1}$, Carmen Fernández-Echeverría ${ }^{1}$, Jara González-Silva ${ }^{1}$ \\ Fernando Claver ${ }^{1}$, M. Perla Moreno ${ }^{1}$
}

\begin{abstract}
The objective of this study was to determine the variables that predicted serve efficacy in elite men's volleyball, in sets with different quality of opposition. 3292 serve actions were analysed, of which 2254 were carried out in high quality of opposition sets and 1038 actions were in low quality of opposition sets, corresponding to a total of 24 matches played during the Men's European Volleyball Championships held in 2011. The independent variables considered in this study were the serve zone, serve type, serving player, serve direction, reception zone, receiving player and reception type; the dependent variable was serve efficacy and the situational variable was quality of opposition sets. The variables that acted as predictors in both high and low quality of opposition sets were the serving player, reception zone and reception type. The serve type variable only acted as a predictor in high quality of opposition sets, while the serve zone variable only acted as a predictor in low quality of opposition sets. These results may provide important guidance in men's volleyball training processes.
\end{abstract}

Key words: match analysis, serve, volleyball, multinomial logistic regression.

\section{Introduction}

Volleyball is a dynamic sport and as such, it has an unpredictable nature despite the fact that its logic is deterministic, being organised into six skills (serve, attack, block, reception, set and defence) with sequential and chronological logic (Buscá and Febre, 2012).

Volleyball structure is basically divided into two game complexes: K1 complex (attack) and K2 complex (defence) (Palao and Santos, 2004). These complexes are mainly comprised of two groups of actions that determine the individual and group performance of a team (Silva et al., 2013): continuity or intermediate actions, and terminal actions. Continuity or intermediate actions favour the game sequence, but their aim is not to achieve the point. These actions include reception, setting and defence (Gil et al., 2011). Terminal actions seek to obtain the point and these include the serve, attack and block (Drikos and Vagenas, 2011; Marcelino et al., 2008; Silva et al., 2013).

Our research focused on studying the terminal serve action, which is the game action that has the second highest correlation with achieving the point (Drikos and Vagenas, 2011; Marcelino et al., 2008), the first being the attack (Palao and Santos, 2004), and the third the block (Marcelino et al., 2008).

The serve is an offensive technical-tactical action that has significant influence on subsequent actions (Asterios et al., 2009). The two main objectives of the serve are to score a direct point and make it difficult for the opposite team to construct the attack (Ureña et al., 2002) reducing first tempo attacks and improving block performance (Papadimitriou et al., 2004).

A large number of studies have focused on determining the main characteristics of the

1 - Faculty of Sport Science. University of Extremadura, Spain 
serve and how this affects the subsequent reception, construction of the attack, and the block. Thus, they have basically tried to associate the different serve and reception variables with serve efficacy or reception performance. The main serve and reception variables considered in these studies were the serve zone, serve type, serve direction (Afonso et al., 2012), serve speed (Moras et al., 2008), risk assumed by the server (Marcelino et al., 2008), reception zone and receiving player (Afonso et al., 2012; Fernandez-Echeverria et al., 2015). The variables that have shown significant association with serve efficacy at high level are essentially the serve type, reception zone and receiving player (Afonso et al., 2012).

On the other hand, there has been a considerable increase in notational studies over the last few years that analysed the interaction and influence of situational variables on players' performance and behaviour (McGarry et al., 2013). Noteworthy among them are those that refer to the game location (Marcelino et al., 2009b), score (Almeida et al., 2014) or quality of opposition (Lago et al., 2013).

Specifically in volleyball, match analysis studies consider situational variables such as match status (Marcelino et al., 2011, 2012), game location (Marcelino et al., 2009b), rotation (Silva et al., 2013), match period (Marcelino et al., 2012) and quality of opposition (Marcelino et al., 2011).

In volleyball, the match status situational variable has been incorporated into several studies, based on the hypothesis that teams play differently depending on the result at certain moments of the game, as expressed by the scoreboard. Thus, Marcelino et al. (2011) verified that teams took more risky decisions in all game actions when there was a considerable difference in the score, and they carried out safer tactical options when the score was more balanced.

Different researchers have studied the match period as a variable that affects the teams' performance (Marcelino et al., 2009a, 2012). Marcelino et al. (2009a) pointed out that the first and fifth sets in volleyball were the sets where team performance may vary the most, due to actions such as reception, setting and defence. Yet, with respect to the moment in the set, Marcelino et al. (2012) showed that players took more risk in their serves during the first 15 points as the points were not decisive, but they rather avoided taking risk during the last points.

On the other hand, authors such as Almeida et al. (2014) in soccer, and García et al. (2014) in basketball, studied how the game location affected the main variables determining team performance. In volleyball, a study by Marcelino et al. (2009b) revealed that local teams won the first, fourth and fifth sets more frequently, carrying out more risky actions during these sets, especially in the attack and block.

Another situational variable is team rotation, considering the position that the setter is in. In their study, Silva et al. (2013) verified that the serve was one of the most discriminating variables of the game result when setters were in the front-court zone $(2,3$ and 4$)$.

Finally, another situational variable that authors attach a lot of importance to is quality of opposition, as this may cause teams to behave differently depending on the opponent (Almeida et al., 2014; Lago et al., 2013). The same aspect was pointed out by Marcelino et al. (2011) in their study on volleyball, indicating that teams took different decisions depending on the quality of opposition. Other studies measure the quality of opposition depending on the final game score, as was the case of Lorenzo et al. (2010) in basketball, who found that the variables predicting victory or defeat normally differed when balanced games were compared with more one-sided games. In volleyball, Drikos and Vagenas (2011) indicated that there were ambivalent sets, safe sets and unbalanced sets, underlining the importance of the attack, above all in ambivalent sets.

In our study, and in line with the works indicated above, the quality of opposition was taken into account, considering the final score of the set for this purpose. Thus, the team did encounter greater opposition in close sets, with a difference in the final score of five points or less (Drikos and Vagenas, 2011).

Due to a small number of predictive studies that have taken situational variables into account, in sport in general and in volleyball in particular, the objective of this study was to determine the variables that predicted serve efficacy in high-level volleyball, considering the quality of opposition sets. To this end, the teams' scores at the end of the set were taken into account. We hypothesized that variables predicting serve efficacy would be different in 
high compared to low quality of opposition sets.

\section{Methods}

\section{Sample}

The study sample was comprised of 3292 serve actions observed in 16 teams that participated in the Men's European Volleyball Championships held in 2011. More specifically, 2254 serve actions were carried out in high quality of opposition sets (sets in which both teams reached a score of 20 points or more) and 1038 serve actions were carried out in low quality of opposition sets (sets in which one of the two teams had a score of under 20 points).

The entire first phase of the Championships, including three matches played by each one of the 16 participating teams, was observed. A total of 87 sets were analysed, 57 of which were high quality of opposition sets and 30 were low quality of opposition sets.

\section{Variables}

The dependent variable considered in our study was serve efficacy, defined as the performance or effect obtained with the serve. In order to assess the efficacy, the FIVB system criteria were used, as in previous studies (Fernández-Echeverria et al., 2015). Three levels were established: (I) permits attacking, "serve that permits the construction of an attack, with all the attack options"; (II) does not permit attacking, "serve that limits the attack options, not permitting first tempo attacks"; (III) point or free ball, "serve that directly scores a point or is returned to the opposite court without being attacked".

The independent variables considered in our study were divided into two groups: serve variables and reception variables.

The serve variables were:

(a) Serve zone, defined as the zone from where the player served, covering a $9 \mathrm{~m}$ wide space located behind the baseline of the court and as an extension to the sidelines of the court, differentiating three zones of origin: zone 1 , zone 6 and zone 5 (Fernández-Echeverría et al., 2015).

(b) Serve type, defined as the type of serve used by the player: jump float serve or tennis jump serve (Afonso et al., 2012).

(c) Serving player, defined as the in-game role of the player serving: setter, attacker receiver, middle attacker or opposite (Afonso et al., 2012; Quiroga et al., 2010).

(d) Serve direction, defined as the direction determined by the serve depending on the serve zone and reception zone: parallel, mid cross-court and long cross-court (Moreno et al., 2007).

The reception variables were:

(e) Reception zone (Figure 1), defined as the zone where the serve was received, adapted from Afonso et al. (2012): zone 1, frontcourt ( $3 \times 9 \mathrm{~m}$ front-court zone); zone 2 , space between players (conflict zone between receiving players in the back-court zone); zone 3 , sides and back-court zone ( $0.5 \mathrm{~m}$ wide zone from the sidelines and from the baseline, in back-court zone) and zone 4, central zone (rest of the back-court zone).

(f) Receiving player, defined as the in-game role of the player that the serve was aimed at, adapted from Afonso et al. (2012): front receiver, back receiver, libero and other.

(g) Reception type, defined as the reception technique used (Afonso et al., 2012), with the following categories: low reception and others (using the forearm pass and other receptions), high reception (reception performed with an overhand pass).

\section{Procedures}

The video data were used for analysis. The matches were recorded using a SONY HDRXR155 digital camera (M2TS format). The camera was located at one of the ends of the court, at a height of $5 \mathrm{~m}$ above the floor level and a distance of $7 \mathrm{~m}$ behind the baseline, to obtain an optimal line of sight.

A systematic observation of different variables was carried out. To validate the observation system created, this was submitted to the criterion of four researchers (Level III volleyball coaches with experience in research and analysis of volleyball performance).

To assess the reliability of observations, after collecting the video footage and prior to the coding process, one observer (an observer with a degree in Physical Activity and Sport Science, and a National Level III Volleyball coach) was trained to appraise and encode game actions, undergoing a training process that used samples with different characteristics, in different sessions. 
These exceeded $10 \%$ of the total sample (203 serves) as indicated by Tabachnick and Fidell (2007). In all the variables observed, the intraobserver Cohen's Kappa values were higher than .81 in the sixth training session, which was the minimum value considered as almost perfect agreement (Landis and Koch, 1977). To guarantee the time reliability of the measurement, the same coding was carried out on two occasions, 10 days apart, obtaining Cohen's Kappa values of over 81 . The observation software applied to volleyball, "VA-Sports" version 1.0.70, was used to analyse the matches (DSD, 2014).

\section{Statistical Analysis}

The absence of multicollinearity had previously been verified through the level of tolerance and inflation factor (VIF). The tolerance values of the model were greater than $50 \%$, thus there were no collinearity problems, as the values were far away from 0 . The inflation factor values of the model were less than 5, implying the absence of collinearity, as the acceptable value of VIF is 5 or less than 5 (Kleinbaum et al., 1988).

A multinomial logistic regression analysis was performed to obtain the estimated probability of occurrence of the dependent variable based on the values of the independent variables in two different contexts (high quality of opposition sets and low quality of opposition sets). The level of significance was set at $p<.05$.

The association of each independent variable with the dependent variable (crude odds ratio) was verified to determine which variables presented statistical significance and thus enter them into an adjusted model (adjusted odds ratio). This step provided information about which independent variables contributed to predicting the dependent variable.

\section{Results}

\section{Inferential analysis}

Below, we will try to verify the associations between the independent variables considered in the study and serve efficacy. To this end, we present the inferential analysis based on the contingency tables, including chi-squared and Cramer's V values. Prior to this, the necessary conditions were guaranteed to validly apply the chi-squared test (the expected minimum frequency greater than one and no more than $20 \%$ of the cells of the table with less than five expected frequencies). The statistical significance level considered was $p<.05$.

In Table 1, the values of the test for each association are presented, as well as the chisquared and Cramer's V values, in high and low quality of opposition sets.

All variables, except the serving player and serve direction, presented a significant association with the dependent variable, in both high and low quality of opposition sets. These two variables may not be included in the multinomial logistic regression model.

\section{Predictive analysis of the serve efficacy}

In Table 2, the results from the complete multinomial logistic regression model are presented, including the variables that may predict serve efficacy in high and low quality of opposition sets (serve zone, server player, serve type, reception zone and reception type).

In high quality of opposition sets, it was observed that the execution of the serve by the setter, instead of by the middle attacker, reduced the frequency $(\mathrm{OR}=0.550)$ of the serve leading to a point or a free-ball, rather than permitting the opposite team to attack. On the other hand, the execution of the tennis jump serve, instead of the jump float serve, increased the frequency $(\mathrm{OR}=$ 1.477) of the serve not permitting an attack, rather than permitting the opposite team to attack. Furthermore, the execution of the tennis jump serve, instead of the jump float serve, increased the frequency $(\mathrm{OR}=2.532)$ of the serve leading to a point or a free-ball, rather than permitting the opposite team to attack.

In turn, the execution of the serve towards the side and back zones, instead of central zones, increased the frequency $(\mathrm{OR}=2.033)$ of the serve not permitting an attack, rather than permitting the opposite team to attack. Moreover, the execution of the serve towards the space between players, instead of central zones, increased the frequency $(\mathrm{OR}=1.925)$ of the serve leading to a point or a free-ball, rather than permitting the opposite team to attack. Likewise, the execution of the serve towards the side and back zones, instead of central zones, increased the frequency $(\mathrm{OR}=$ 4.711) of the serve leading to a point or a free-ball, rather than permitting the opposite team to attack.

Finally, the execution of low reception and others, instead of high reception, increased the frequency $(\mathrm{OR}=3.606)$ of the serve leading to a 
point or a free-ball, rather than permitting the opposite team to attack.

In low quality of opposition sets, we observed that the execution of the serve from zone 1 instead of from zone 6 reduced the frequency $(\mathrm{OR}=0.587)$ of the serve leading to a point or a free-ball, rather than permitting the opposite team to attack. On the other hand, the execution of the serve by the opposite, instead of by the middleattacker, increased the frequency $(\mathrm{OR}=1.577)$ of the serve not permitting an attack, rather than permitting the opposite team to attack.
In turn, the execution of the serve towards the side and back zones, instead of towards the central zones, increased the frequency $(\mathrm{OR}=$ 4.269) of the serve leading to a point or a free-ball, rather than permitting the opposite team to attack.

Finally, the execution of low reception and others, instead of high reception, increased the frequency $(\mathrm{OR}=1.904)$ of the serve not permitting an attack rather than permitting the attack on the opposite team. Likewise, low reception and others, instead of high reception, increased the frequency of the serve leading to a point or a freeball, rather than permitting the opposite team to attack $(\mathrm{OR}=5.334)$.

\section{Table 1}

Relationships between independent variables and the dependent variable,

in high and low quality of opposition sets.

High quality opposition set Low quality opposition set

\begin{tabular}{lcccccc}
\hline & & & & & & \\
& $\mathrm{X}^{2}$ & $p$ & Cramer's V & $\mathrm{X}^{2}$ & $p$ & Cramer's V \\
& & & & & & \\
& & & & & & \\
\hline Serve zone & 10.077 & .039 & .047 & 11.869 & .018 & .076 \\
Serving player & 31.288 & .000 & .083 & 21.020 & .002 & .101 \\
Serve type & 72.076 & .000 & .179 & 36.514 & .000 & .188 \\
Reception zone & 132.063 & .000 & .171 & 58.528 & .000 & .168 \\
Reception type & 36.797 & .000 & .129 & 32.309 & .000 & .178 \\
Receiving player & 2.494 & .869 & .024 & 7.626 & .267 & .061 \\
Serve direction & 6.127 & .409 & .037 & 3.825 & .700 & .043 \\
\hline
\end{tabular}




\section{Table 2}

Adjusted model for serve effectiveness. Variables related to the serve

(high quality of the opposition set, low quality of the opposition set)

\begin{tabular}{|c|c|c|c|c|c|c|c|c|c|}
\hline $\begin{array}{c}\text { Serve } \\
\text { variables }\end{array}$ & $\begin{array}{c}\text { Permits } \\
\text { attacking }^{\mathrm{a}} \\
\%\end{array}$ & $\begin{array}{c}\text { Does not } \\
\text { permit } \\
\text { attacking } \\
\%\end{array}$ & $\begin{array}{c}\text { OR } \\
\text { Crude }\end{array}$ & $\begin{array}{c}\text { OR } \\
\text { Ajusted }\end{array}$ & $p$ & $\begin{array}{c}\text { Point/ } \\
\text { Free } \\
\text { ball } \\
\%\end{array}$ & $\begin{array}{c}\text { OR } \\
\text { Crude }\end{array}$ & $\begin{array}{c}\text { OR } \\
\text { Ajusted }\end{array}$ & $p$ \\
\hline
\end{tabular}

\section{Serve zone}

High quality of opposition set

Zone $5 \quad 46.2 \% \quad 45.1 \%$ $\begin{array}{cc}1.119 & 1.096 \\ (0.897-1.397)^{\mathrm{c}} & (0.873-1.375)^{\mathrm{c}}\end{array}$

0.873

$(0.687-1.109)^{\mathrm{c}}$

1.017
$(0.791-1.307)$

.895

1.298

1.506 $(0.903-1.866)^{c} \quad(0.999-2.271)^{c}$

Zone $6^{\text {b }}$

$42.5 \%$

$47.6 \%$

$(0.791-1.307)^{\mathrm{c}}$

0.816

1.457

$(0.541-1.229)^{c} \quad(0.905-2.346)^{c}$

$9.8 \%$

Low quality of opposition set

$\begin{array}{lll}\text { Zone } 1 & 38.3 \% & 45.6 \%\end{array}$

$\begin{array}{lll}\text { Zone } 5 & 42.3 \% & 47.0 \%\end{array}$

0.795

$(0.571-1.109)^{c}$

0.741

0.744

(0.524-1.056)

0.918

$(0.508-1.042)^{c}$

$(0.612-1.378)^{c}$

$097 \quad 16.1 \%$

$10.7 \%$

0.659

$(0.431-1.007)^{\mathrm{c}}$

0.395

$(0.230-0.678)^{c}$

$20.4 \%$

Zone $6^{\mathrm{b}} \quad 31.9 \% \quad 47.8 \%$

\section{Serving player}

High quality of opposition set

\begin{tabular}{|c|c|c|c|c|c|c|c|c|}
\hline Opposite & $32.6 \%$ & $52.9 \%$ & $\begin{array}{c}1.636 \\
(1.235-2.168)^{c}\end{array}$ & $\begin{array}{c}1.217 \\
(0.889-1.665)^{c}\end{array}$ & .221 & $14.4 \%$ & $\begin{array}{c}2.124 \\
(1.389-3.247)^{c}\end{array}$ & $\begin{array}{c}1.066 \\
(0.644-1.765)^{c}\end{array}$ \\
\hline $\begin{array}{l}\text { Attacker } \\
\text { receiver }\end{array}$ & $40.2 \%$ & $47.7 \%$ & $\begin{array}{c}1.196 \\
(0.962-1.488)^{c}\end{array}$ & $\begin{array}{c}0.972 \\
(0.766-1.233)^{c}\end{array}$ & .816 & $12.2 \%$ & $\begin{array}{c}1.455 \\
(1.023-2.070)^{c}\end{array}$ & $\begin{array}{c}0.841 \\
(0.559-1.267)^{c}\end{array}$ \\
\hline Setter & $46.5 \%$ & $47.4 \%$ & $\begin{array}{c}1.028 \\
(0.807-1.310)^{c}\end{array}$ & $\begin{array}{c}0.981 \\
(0.766-1.258)^{c}\end{array}$ & .882 & $6.1 \%$ & $\begin{array}{c}0.630 \\
(0.393-1.009)^{c}\end{array}$ & $\begin{array}{c}0.550 \\
(0.331-0.913)^{c}\end{array}$ \\
\hline $\begin{array}{l}\text { Middle } \\
\text { attacker }{ }^{b} \\
\text { Low quali }\end{array}$ & $45.5 \%$ & $45.1 \%$ & & & & $9.5 \%$ & & \\
\hline Opposite & $28.3 \%$ & $52.2 \%$ & $\begin{array}{c}1.689 \\
(1.121-2.544)^{c}\end{array}$ & $\begin{array}{c}1.577 \\
(1.005-2.476)^{c}\end{array}$ & .048 & $19.4 \%$ & $\begin{array}{c}1.989 \\
(1.160-3.409)^{c}\end{array}$ & $\begin{array}{c}1.454 \\
(0.778-2.717)^{c}\end{array}$ \\
\hline $\begin{array}{l}\text { Attacker } \\
\text { receiver }\end{array}$ & $33.4 \%$ & $48.2 \%$ & $\begin{array}{c}1.321 \\
(0.949-1.840)^{c}\end{array}$ & $\begin{array}{c}1.215 \\
(0.849-1.737)^{c}\end{array}$ & .287 & $18.3 \%$ & $\begin{array}{c}1.590 \\
(1.015-2.491)^{\mathrm{c}}\end{array}$ & $\begin{array}{c}1.300 \\
(0.778-2.170)^{c}\end{array}$ \\
\hline Setter & $48.3 \%$ & $40.8 \%$ & $\begin{array}{c}0.774 \\
(0.525-1.143)^{c}\end{array}$ & $\begin{array}{c}0.863 \\
(0.568-1.312)^{c}\end{array}$ & .491 & $10.9 \%$ & $\begin{array}{c}0.655 \\
(0.362-1.188)^{c}\end{array}$ & $\begin{array}{c}0.819 \\
(0.422-1.587)^{c}\end{array}$ \\
\hline $\begin{array}{l}\text { Middle } \\
\text { attacker }^{\mathrm{b}}\end{array}$ & $41.0 \%$ & $44.8 \%$ & & & & $14.2 \%$ & & \\
\hline
\end{tabular}

\section{Serve type}

High quality of opposition set

\begin{tabular}{|c|c|c|c|c|c|c|c|c|}
\hline $\begin{array}{l}\text { Tennis } \\
\text { jump } \\
\text { serve }\end{array}$ & $35.5 \%$ & $50.5 \%$ & $\begin{array}{c}1.649 \\
(1.382-1.968)^{c}\end{array}$ & $\begin{array}{c}1.477 \\
(1.185-1.841)^{c}\end{array}$ & .001 & $14.0 \%$ & $\begin{array}{c}3.511 \\
(2.530-4.874)^{c}\end{array}$ & $\begin{array}{c}2.532 \\
(1.674-3.830)^{c}\end{array}$ \\
\hline Jump & $50.7 \%$ & $43.7 \%$ & & & & $5.7 \%$ & & \\
\hline
\end{tabular}

Jump

serve $^{b}$

Low quality of opposition set

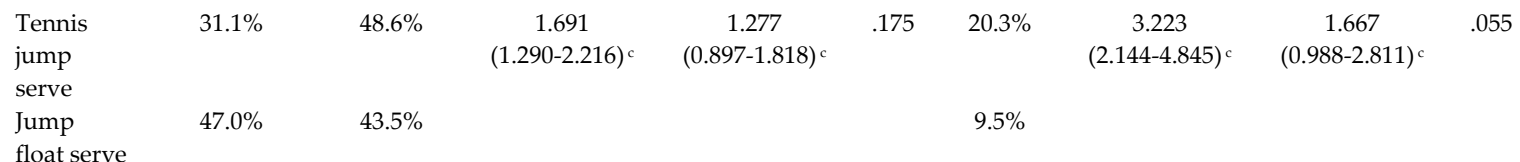

float serve

" $a$ " Category of reference for the dependent variable. " $b$ " Category of references for the independent variables. " $c$ " Numbers in brackets refer to the $95 \%$ confidence interval. 
Table 3

Adjusted model for serve effectiveness. Variables related to the reception (high quality of the opposition set, low quality of the opposition set)

\begin{tabular}{|c|c|c|c|c|c|c|c|c|c|}
\hline $\begin{array}{c}\text { Serve } \\
\text { variables }\end{array}$ & $\begin{array}{c}\text { Permits } \\
\text { attackinga } \\
\%\end{array}$ & $\begin{array}{c}\text { Does not } \\
\text { permit } \\
\text { attacking } \\
\%\end{array}$ & $\begin{array}{c}\text { OR } \\
\text { Crude }\end{array}$ & $\begin{array}{c}\text { OR } \\
\text { Ajusted }\end{array}$ & $p$ & $\begin{array}{c}\text { Point/ } \\
\text { Free ball } \\
\%\end{array}$ & $\begin{array}{c}\text { OR } \\
\text { Crude }\end{array}$ & $\begin{array}{c}\text { OR } \\
\text { Ajusted }\end{array}$ & $p$ \\
\hline
\end{tabular}

\section{Reception zone}

High quality of opposition set

\begin{tabular}{|c|c|c|c|c|c|c|c|c|c|}
\hline $\begin{array}{l}\text { Front-court } \\
\text { zone }\end{array}$ & $37.8 \%$ & $40.0 \%$ & $\begin{array}{c}0.959 \\
(0.491-1.872)^{\mathrm{c}}\end{array}$ & $\begin{array}{c}0.959 \\
(0.488-1.884)^{c}\end{array}$ & .904 & $22.2 \%$ & $\begin{array}{c}3.289 \\
(1.477-7.325)^{c}\end{array}$ & $\begin{array}{c}2.042 \\
(0.779-5.354)^{c}\end{array}$ & .147 \\
\hline $\begin{array}{l}\text { Space } \\
\text { between } \\
\text { players }\end{array}$ & $40.8 \%$ & $45.3 \%$ & $\begin{array}{c}1.005 \\
(0.735-1.374)^{c}\end{array}$ & $\begin{array}{c}0.998 \\
(0.727-1.372)^{c}\end{array}$ & .992 & $13.9 \%$ & $\begin{array}{c}1.909 \\
(1.201-3.035)^{c}\end{array}$ & $\begin{array}{c}1.925 \\
(1.197-3.096)^{c}\end{array}$ & .007 \\
\hline $\begin{array}{l}\text { Sides and } \\
\text { back-court } \\
\text { zone }\end{array}$ & $20.0 \%$ & $42.3 \%$ & $\begin{array}{c}1.915 \\
(1.190-3.082)^{c}\end{array}$ & $\begin{array}{c}2.033 \\
(1.257-3.287)^{c}\end{array}$ & .004 & $37.7 \%$ & $\begin{array}{c}10.538 \\
(6.348-17.495)^{c}\end{array}$ & $\begin{array}{c}4.711 \\
(2.494-8.897)^{c}\end{array}$ & .000 \\
\hline $\begin{array}{l}\text { Central } \\
\text { zone }^{\mathrm{b}}\end{array}$ & $43.8 \%$ & $48.4 \%$ & & & & $7.8 \%$ & & & \\
\hline \multicolumn{10}{|c|}{ Low quality of opposition set } \\
\hline $\begin{array}{l}\text { Front-court } \\
\text { zone }\end{array}$ & $18.2 \%$ & $54.5 \%$ & $\begin{array}{c}2.528 \\
(0.507-12.604)^{c}\end{array}$ & $\begin{array}{c}2.966 \\
(0.571-15.421)^{c}\end{array}$ & .196 & $27.3 \%$ & $\begin{array}{c}4.350 \\
(0.718-26.337)^{c}\end{array}$ & $\begin{array}{c}1.730 \\
(0.145-20.631)^{c}\end{array}$ & .665 \\
\hline $\begin{array}{l}\text { Space } \\
\text { between } \\
\text { players }\end{array}$ & $34.0 \%$ & $49.0 \%$ & $\begin{array}{c}1.214 \\
(0.767-1.924)^{c}\end{array}$ & $\begin{array}{c}1.250 \\
(0.782-1996)^{c}\end{array}$ & .351 & $17.0 \%$ & $\begin{array}{c}1.450 \\
(0.782-2.690)^{c}\end{array}$ & $\begin{array}{c}1.130 \\
(0.567-2.251)^{c}\end{array}$ & .728 \\
\hline $\begin{array}{l}\text { Sides and } \\
\text { back-court } \\
\text { zone }\end{array}$ & $13.0 \%$ & $32.6 \%$ & $\begin{array}{c}2.107 \\
(0.809-5.488)^{c}\end{array}$ & $\begin{array}{c}2.271 \\
(0.857-2.017)^{c}\end{array}$ & .099 & $54.3 \%$ & $\begin{array}{c}12.083 \\
(4.840-30.165)^{c}\end{array}$ & $\begin{array}{c}4.269 \\
(1.396-13.056)^{c}\end{array}$ & .011 \\
\hline $\begin{array}{l}\text { Central } \\
\text { zone }^{\mathrm{b}}\end{array}$ & $39.5 \%$ & $46.9 \%$ & & & & $13.6 \%$ & & & \\
\hline
\end{tabular}

\section{Reception type}

High quality of opposition set

\begin{tabular}{|c|c|c|c|c|c|c|c|c|c|}
\hline $\begin{array}{l}\text { Low } \\
\text { reception }\end{array}$ & $40.6 \%$ & $49.5 \%$ & $\begin{array}{c}1.693 \\
(1.313-2.185)^{c}\end{array}$ & $\begin{array}{c}1.318 \\
(0.995-1.744)^{c}\end{array}$ & .054 & $10.0 \%$ & $\begin{array}{c}6.702 \\
(2.923-15.368)^{c}\end{array}$ & $\begin{array}{c}3.606 \\
(1.512-8.600)^{c}\end{array}$ & .004 \\
\hline $\begin{array}{l}\text { High } \\
\text { reception } \\
\text { and other }{ }^{b} \\
\text { Low quality }\end{array}$ & position & $41.0 \%$ & & & & $2.1 \%$ & & & \\
\hline $\begin{array}{l}\text { Low } \\
\text { reception }\end{array}$ & $35.4 \%$ & $49.1 \%$ & $\begin{array}{c}2.279 \\
(1.531-3.393)^{c}\end{array}$ & $\begin{array}{c}1.904 \\
(1.233-2.940)^{c}\end{array}$ & .004 & $15.5 \%$ & $\begin{array}{c}8.079 \\
(2.896-22.535)^{c}\end{array}$ & $\begin{array}{c}5.334 \\
(1.841-15.454)^{c}\end{array}$ & .002 \\
\hline $\begin{array}{l}\text { High } \\
\text { reception } \\
\text { and other }{ }^{b}\end{array}$ & $60.2 \%$ & $36.6 \%$ & & & & $3.3 \%$ & & & \\
\hline
\end{tabular}

" $a$ " Category of reference for the dependent variable. " $b$ " Category of references for the independent variables. "c" Numbers in brackets refer to the $95 \%$ confidence interval. 


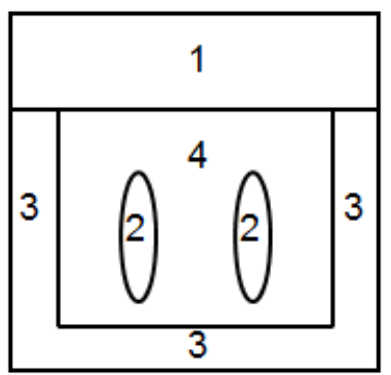

Figure 1

Topographical model for the reception zone.

\section{Discussion}

The main objective of this study was to determine the variables that predicted serve efficacy in high-level men's volleyball, in sets with different quality of opposition. The variables that acted as predictors of serve efficacy in high quality of opposition sets and low quality of opposition sets were the serving player, reception zone and reception type. Coinciding with our results, Afonso et al. (2012) found that the serving player, in men's high-level volleyball, proved to be a predictor of serve efficacy.

In our study, it was shown through a regression analysis that in high quality of opposition sets, if the serve was carried out by the setter instead of by the middle attacker, the frequency of obtaining a point or free-ball decreased. In contrast, in low quality of opposition sets, it was shown that if the serve was carried out by the opposite instead of by the middle player, the frequency of not permitting the opposite team to attack increased. Afonso et al. (2012), in their study carried out on high-level male volleyball players, coincided with our results in low quality of opposition sets, indicating that the frequency of the opposite team not carrying out a perfect reception was greater if the serve was executed by any player other than the middle attacker.

The results encountered in our study may be due to differences in the technique of execution of the serve action between players who performed different in-game roles.

In our study, the reception zone was a predictor of serve efficacy in high and low quality of opposition sets, the prediction being greater in high quality of opposition sets. This coincided with the findings of Afonso et al. (2012), although the quality of opposition was not taken into account.

More specifically, the regression analysis showed that in high quality of opposition sets, serving towards the side and back zones increased the frequency of not permitting the opposite team to attack, as well as achieving a point or free-ball; and serving towards the space between players increased the frequency of obtaining a point or free-ball. In low quality of opposition sets, it was also observed that there was an increase in frequency of obtaining a direct point or free-ball if the ball was sent towards the side and back zones. Along this line, authors such as Moreno et al. (2007) and Afonso et al. (2012) 
verified that serves aimed close to the baseline and those aimed at the corners at the back of the court, were significantly and positively associated with a direct point. López-Martínez and Palao (2009) also verified in beach volleyball that serves aimed at the seam between the receiver players were the most effective.

The results obtained in our study showed that serving towards the space between players increased the frequency of obtaining a direct point or free-ball in high quality of opposition sets. This aspect did not appear in low quality of opposition sets. This may mean that in high quality of opposition sets, where all points may be decisive due to the teams being evenly matched, the players try to take advantage of the space between players by creating a conflict in receiving players and thus, improve serve efficacy (FernándezEcheverría et al., 2015; López-Martínez and Palao, 2009).

The reception type was also a predictor of serve efficacy regardless of the quality of opposition sets. More specifically, in our study, there was an increase in the frequency of serves that ended with a point scored or free-ball rather than permitting the construction of the attack, if it was a forearm reception or any other type of reception. In low quality of opposition sets, there was an increase in frequency of the serve not permitting the opposite team to carry out an attack, rather than permitting it to attack, if it was a forearm reception or any other type of reception. Thus, low reception and others, rather than high reception, increase the probability of decreasing the reception efficacy. These results, however, do not coincide with those of Palao et al. (2009), who found that low reception increased efficacy in the construction of the subsequent attack. This efficacy was greater in men than in women. They do not coincide, either, with the results of Ureña et al. (2002), who indicated a higher percentage of perfect receptions if low reception, rather than high reception, was carried out.

Our results may be due to the fact that, when high reception was carried out, the chance of a better reception increased, as also indicated by Afonso et al. (2012). In agreement with this, it may be concluded that players decide to receive with high reception when the serve path is not descending and the serve is not fast. Therefore, for greater serve efficacy, teams must serve in such a way as to prevent the opposition from using high reception; in other words, the serve should be fast and have a descending path (Ureña et al., 2002).

The serve type only acted as a predictor of serve efficacy in high quality of opposition sets. More specifically, tennis jump serves permitted an increase in frequency of obtaining a direct point or free-ball, rather not permitting the opposite team to attack. This tells us that players seek to hinder the construction of the opponents' attack as much as possible when the sets played are close, although by doing this, they run a greater risk. In line with our results, Afonso et al. (2012) found that the use of the tennis jump serve instead of the jump float serve represented greater probability of sending the reception ball to a nonacceptable setting zone. However, these results do not coincide with the serve type chosen by the players when the scoreboards are level during the set, which is when players decide to assume less risk (Marcelino et al., 2011).

The serve zone only acted as a predictor variable in low quality of opposition sets. In the majority of studies at high-level, despite zone 1 being the most frequent zone in the serve execution, there was no association between the serve zone and serve efficacy (Moreno et al., 2007). These results may be due to the fact that, as zone 1 is the most commonly used to carry out the serves, receiving players were used to receiving serves from this zone and therefore, found it less difficult to construct the attack under these circumstances.

Finally, the variables that did not act as predictors of serve efficacy in both high and low quality of opposition sets were the serve direction and receiving player. The serve direction was not significantly associated with serve efficacy in either of the quality of opposition sets. These results coincide with those found by Afonso et al. (2012) in high level men's volleyball, probably due to the fact that this is not an essential element in serve efficacy. With respect to the receiving player variable, and in contrast to our results, the study by Afonso et al. (2012) showed that if the reception was carried out by any other player but the libero, reception efficacy decreased, mostly aiming the reception at a non-acceptable setting zone.

The results obtained may be due to the similarity in reception levels of the players who 
participated in our study sample, as well as to the limited influence that sending to certain receiving players (forwards) has on the construction of the subsequent attack, and the fact that serving players choose to evaluate other aspects or take advantage of other variables to improve serve efficacy.

\section{Conclusions}

The quality of opposition sets affects the serve action of players in elite men's volleyball. In high quality of opposition sets, elite men's volleyball players, as shown in our study sample, must assume greater risk in the serve (using the tennis jump serve instead of the jump float serve, and sending the serve to zones close to the sidelines or to the back of the court, and to the space between players, instead of to central zones of the court) if they wish to increase serve efficacy, as the serve type and reception zone are the two variables that mainly predict its efficacy.

Regardless of the quality of opposition sets, high-level volleyball players, when serving, must try to avoid high reception. To this end, they must serve with descending paths and at high speed.

The receiving player variable, regardless of the quality of opposition sets, does not predict server efficacy in high-level male volleyball. Therefore, serving to players with different game roles does not affect the serve efficacy or the construction of the subsequent attack as, in the study sample, reception efficacy is similar between the attacker receivers and the libero.

These results should be considered in high level male volleyball training processes. Therefore, we suggest that high level coaches should train their players by enforcing serve types (instructing players on managing the risk, using primarily high speed serves to avoid overhand receptions) and the reception zone (trying to serve close to the lines or to the interference zone between receivers).

\section{Acknowledgements}

This work was developed through the project funded by the Ministry of Science and Innovation entitled "MASVb System of competitive assessment and technical guidance for the Spanish Superliga Volleyball" (DEP2011-27503); and this work was supported by the Consejería de Empleo, Empresa e Innovación del Gobierno de Extremadura (Spain) through the European Regional Development fund.

\section{References}

Afonso J, Esteves F, Araujo R, Thomas L, Mesquita I. Tactical determinants of setting zone in elite men's volleyball. J Sport Sci Med, 2012; 11(1): 64-70

Almeida C, Ferreira A, Volossovitch A. Effects of Match Location, Match Status and Quality of Opposition on Regaining Possession in UEFA Champions League. J Hum Kinet, 2014; 41(1): 203-214

Asterios P, Kostantinos C, Athanasios M, Dimitrios K. Comparision of technical skills effectiveness of men`s National Volleyball teams. Int J Perf Anal Sport, 2009; 9: 1-7

Buscá B, Febrer J. Temporal fight between the middle blocker and the setter in high level volleyball. Rev Int Med Cienc Act Fís Deporte, 2012; 12(46): 313-327

Drikos S, Vagenas G. Multivariate assessment of selected performance indicators in relation to the type and result of a typical set in Men's Elite Volleyball. Int J Perf Anal Sport, 2011; 11(1): 85-95

DSD. VA-Sports [Voleibol]. Software de Análisis Observacional aplicado al Voleibol. Desarrollo de Software Deportivo: S.L. León, 2014

Fernández-Echeverría C, Gil A, Moreno A, Claver F, Moreno MP. Analysis of the variables that predict serve efficacy in young volleyball players. Int J Perf Anal Sport, 2015; 15(1): 172-186

García J, Ibáñez S, Gómez M, Sampaio J. Basketball Game-related statistics discriminating ACB league teams according to game location, game outcome and final score differences. Int J Perf Anal Sport, 2014; 14(2): 443-452

Gil A, Del Villar F, Moreno A, García-González L, Moreno MP. Analysis of the efficacy of volleyball serve formation in category. Rev int med cienc act fís deporte, 2011; 11(44): 721-737 
Kleinbaum DG, Kupper LL, Muller KE. Applied Regression Analysis and Other Multivariate Analysis Methods. Boston: PWS-Kent Publishing Company; 1988

Lago C, Gómez MA, Viaño J, González-García I. Home advantage in elite handball: the impact of the quality of opposition on team performance. Int J Perf Anal Sport, 2013; 13(3): 724-733

Landis J, Koch G. The measurement of observer agreement for categorial data. Biometrics, 1977; 33: 159-174 http://dx.doi.org/10.2307/2529310

López-Martínez AB, Palao JM. Effect of Serve Execution on Serve Efficacy in Men's and Women's Beach Volleyball. Internatinal Journal of Applied Sports Sciences, 2009; 21(1): 1-16

Lorenzo A, Gómez MA, Ortega E, Ibáñez SJ, Sampaio J. Game related statistics which discriminate between winning and losing under-16 male basketball games. J Sports Sci Med, 2010; 9: 664-668

Marcelino R, Mesquita I, Afonso J. The weight of terminal actions in Volleyball. Contributions of the spike, serve and block for the teams' rankings in the World League 2005. Int J Perf Anal Spor, 2008; 8(2): 1-7

Marcelino R, Mesquita I, Sampaio J. Study of performance indicators in male volleyball according to the set number. $R$ bras Ci e Mov, 2009a; 16(3): 1-23

Marcelino R, Mesquita I, Sampaio J, Anguera M. Advantage of playing at home in high performance volleyball. Revista de Psicologia del Desporte, 2009b; 18: 181-196

Marcelino R, Mesquita I, Sampaio J. Effects of quality of opposition and match status on technical and tactical performances in elite volleyball. J Sport Sci, 2011; 29(7): 733-741

Marcelino R, Sampaio J, Mesquita I. Attack and serve performances according to the match period and quality of opposition in elite volleyball matches. J Strength Cond Res, 2012; 26(12): 3385-3391

McGarry T, O'Donoghue P, Sampaio J. Routledge handbook of sports performance analysis. Abingdon, UK: Routledge; 2013

Moras G, Peña J, Rodríguez S, Vallejo L, Tous-Fajardo J, Mujika I. A comparative study between serve mode and speed and its effectiveness in a high-level volleyball tournament. J Sports Med Phys Fitness, 2008; 48(1): 31-36

Moreno MP, García AG, Moreno A, Molina J, Santos J. Study of the directions of service in men's volleyball high level. Mot. Eur. J. Hum. Mov, 2007; 18: 111-134

Palao JM, Manzanares P, Ortega E. Techniques used and efficacy of volleyball skills in relation to gender. Int J Perform Anal Sport, 2009; 9(2): 281-293

Palao JM, Santos JA. Effect of team level on skill performance in volleyball. Int J Perform Anal Sport, 2004; 4(2): 50-60

Papadimitriou K, Pashali E, Sermaki I, Mellas S, Papas M. The effect of the opponents' serve on the offensive actions of Greek setters in volleyball games. Int J Perform Anal Sport, 2004; 4(1): 23-33

Quiroga ME, García-Manso JM, Rodríguez-Ruiz D, Sarmiento S, De Saa Y, Moreno MP. Relation between ingame role and service characteristics in elite women's volleyball. J Strength Cond Res, 2010; 24(9): 23162321

Silva M, Lacerda D, João, P. Match analysis of discrimination skills according to the setter attack zone position in high level volleyball. Int J Perform Anal Sport, 2013; 13(2): 452-460

Tabachnick B, Fidell L. Using Multivariate Statistics: 5 ed. Boston: Pearson; 2007

Ureña A, Calvo R, Lozano C. A study of serve reception in the topo-level of spanish male volleybal after the introduction of the libero player. Rev Int Med Cienc Ac, 2002; (4): 37-49

\section{Corresponding author:}

\section{Carmen Fernández Echeverría}

Faculty of Sport Sciences, University of Extremadura, Av. Universidad s/n. 1003. Cáceres

Tel: (+34) 664037328

E-mail: cafernandeze@unex.es 